\title{
CHIMPANCÉ CUBANO
}

POR EL

. DR. LouIS MONTANÉ,

Profesor de Antropología en la Universidad de la Habana.

surean

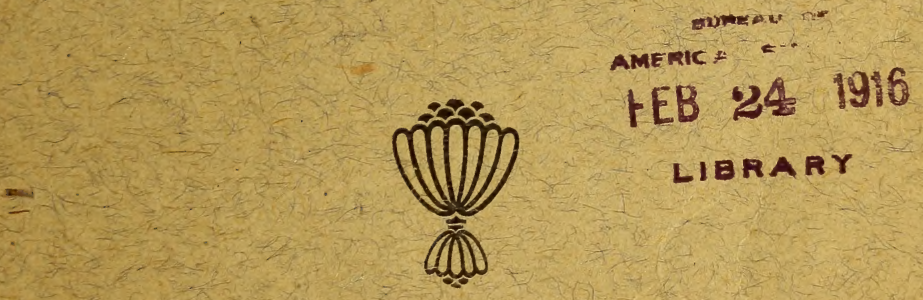



UN CHIMPANCÉ CUBANO. 



\section{UN}

\section{ChIMPANCÉ CUBANO}

POR EL

\section{DR. LOUIS MONTANÉ,}

Profesor de Antropología en la Universidad de la Habana.

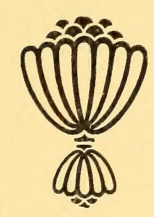




$$
\begin{aligned}
& \text { QL } \\
& 7.37 \\
& P 96 M G 6 \\
& 1915
\end{aligned}
$$




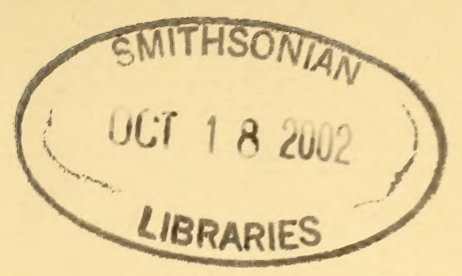

A

LA MEMOIRE

$$
\begin{aligned}
& \text { DE } \\
& \text { MON MẤTRE VENERÉ } \\
& \text { P. BROCA. }
\end{aligned}
$$





\title{
NOTAS SOBRE UN CHIMPANCE NACIDO EN CUBA
}

\author{
TRABAJO LEIDO \\ EN I.A
}

SOCIEDAD CUBANA DE HISTORIA NATURAL "FELIPE POEY "

(SESIÓN DEL 30 DE OCTUBRE DE 1915.)

En una memoria notable sobre $E l$ orden de los Primates. Paralelo anatómico entre el hombre y los monos (París, 1877) Broca, al enunciar que los fenómenos de la gestación y la evolución de ciertas partes de las membranas fetales presentan en los Primates diferencias asaz importantes, declara que en este punto, no se podía sino muy raramente hablar de los antropoides, puesto que estos animales no se reproducen en cautiverio; "y lo poco que se sabe de ellos ha sido observado sobre alguna que otra hembra matada en plena gestación.',

La procreación, pues, y el nacimiento de un chimpancé en Cuba, constituye un acontecimiento científico, digno ciertamente de ser registrado en los anales de las Ciencias Naturales; porque a nuestro entender, es la primera vez que nace en pleno cautiverio un mono antropomorfo.

¡Dulce cautiverio si se piensa que este hermano inferior del hombre ha abierto los ojos a la luz bajo un cielo maravilloso, y a la sombra misma de un castillo, rodeado de un amplio y frondoso parque, imagen reducida de las misteriosas obscuridades de los impenetrables bosques ancestrales! Hecho científico notable, lo repito, que hace exclamar al Dr. Metchnikoff, en una carta dirigida a la acaudalada Sra. Rosalía Abreu, dueña de la "Quinta Palatino"': "Es absolutamente maravilloso lo que se ha podi"do realizar; pues es la primera vez-que yo sepa-, que se ha 
"logrado obtener la reproducción de un mono antropomorfo en "cautiverio. Según todos los datos que me ha sido dado recoger "de los médicos coloniales,-aun en la misma Africa, en Guinea, "en el Congo, nunca se ha podido obtener la reproducción de un "chimpancé. La felicito, pues, por el resultado. Sépalo bien; en "el porvenir ésto presentará una grandísima importancia para el "estudio de las enfermedades infecciosas, tales como escarlatina, “"sarampión, difteria, ete." (París, 29 Agosto, 1915.)

Igual manifestación había anteriormente dirigido a la culta señora el Dr. W. T. Harnaday, director del New York Zoological Park:

"Una vez, dice, tuvimos aquí un pequeño chimpancé con su "madre; pero la madre fué capturada en estado salvaje poco "antes de nacer el chimpancé; y por tanto estaba en estado de “preñez al ser capturada.

"La felicito, pues, calurosamente, y me alegraría mucho re"cibir detalles completos del hecho. Infiero, naturalmente, que el nacimiento tuvo hugar por el cuidado en cautividad. (New York, 21 Julio, 1915.)

Y no ha faltado siquiera, en este asunto, la nota psicológica. El Dr. Robert M. Yerkes, del "Psychological Laboratory", de la Universidad de Harvard, expresa en su carta toda la alegría que le ha producido el acontecimiento científico que vamos a relatar:

"Yo estoy trabajando, dice, sin descanso para obtener la “"creación de una estación americana, en la que podrán ser estu"diados directamente los monos y antropoides, desde el punto de "vista de sus costumbres, relaciones sociales, vida mental, así co"mo desde el punto de vista morfológico, fisiológico y patológico."

"QQué buena fortuna, pues, para todos, que haya nacido en pleno eautiverio un joven chimpancé!.... (30 Septiembre, 1915. Harvard University, Cambridge, Massachusetts.)

Ha llegado, pues, el momento de presentar la familia antropomorfa, de la cual nos vamos a ocupar.

Jimmy, el padre, vino de Londres a la Habana el año próximo pasado de 1914. Este chimpancé adulto (11 a 12 años) mide como talla $1 \mathrm{~m} .13$ cent. Es irascible y feroz. (Fig. núm. 1.)

Cucusa, la madre, chimpancé oruinda de Sierra Leona y adulta (12 a 14 años) es un hermoso ejemplar de mona antropomorfa. Mide como talla $1 \mathrm{~m}$. 30 cent, y su perímetro torácico alcanza 90 cent. 


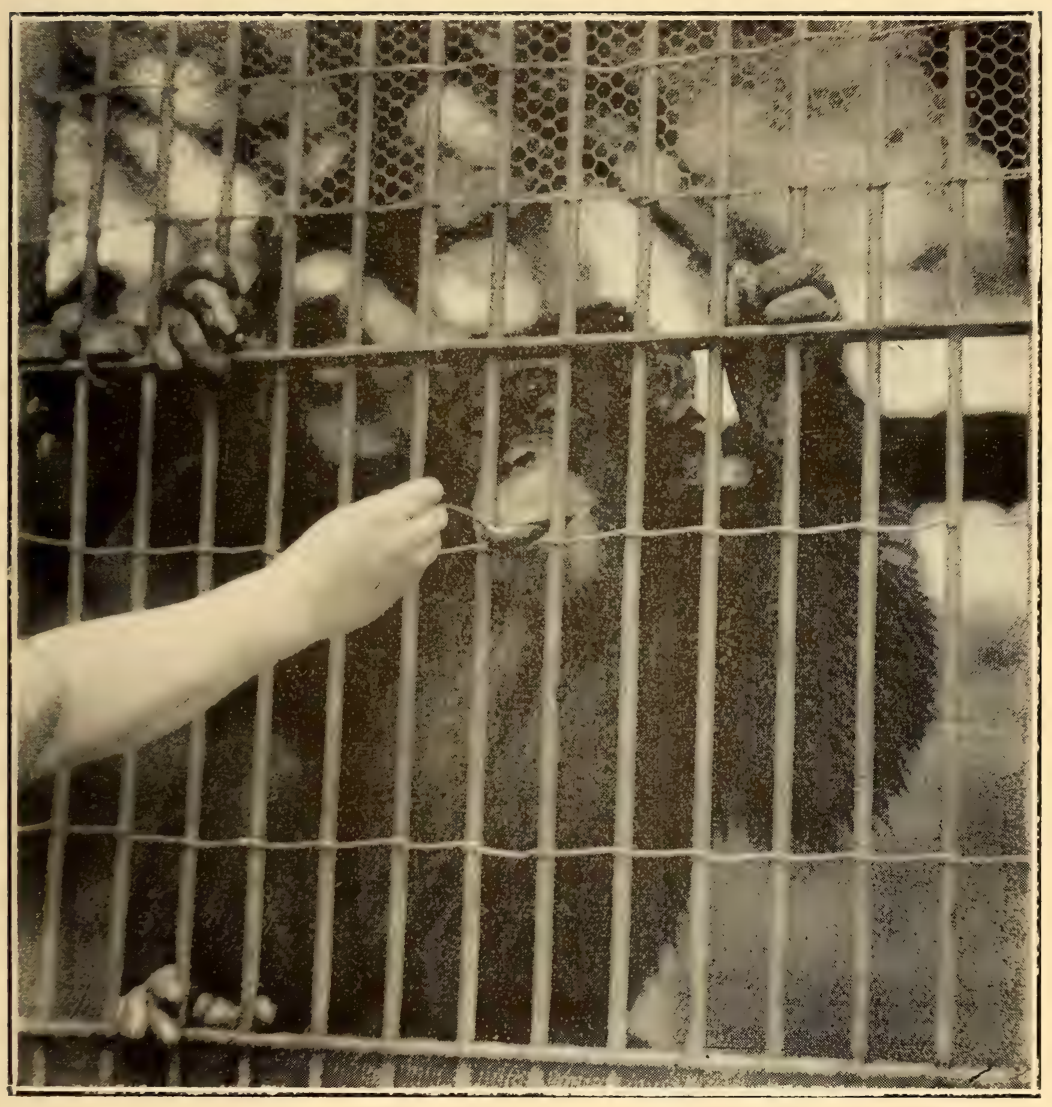

Fig. núm. 1. Jimmy. 

Cucusa había anteriormente contraído relaciones amorosas con Chimpí, chimpancé establecido desde 1904 en el parque de la "Quinta Palatino",-de donde se ha ausentado a veces, acompañando a su dueña en sus viajes por Europa. Era un antropomorfo notable por su inteligencia. Debido a cierta anomalía íntima de su organización física, Chimpi no ha tenido sucesión-, muriendo en abril de 1914 a la edad de 14 an̂os, a consecuencia de mielitis aguda, según los datos fidedignos de la autopsia practicada por el Dr. Raimundo Menocal.

En fin, el joven chimpancé, fruto de los amores de Jimmy y de Cucusa, fué desde el primer momento bautizado con el nombre de Anumá (divinidad simiana de la India), habiendo nacido el 27 de Abril de 1915, fecha de hoy en adelante memorable en el calendario de los alumbramientos de monas antropomorfas.

De Jimmy poco tendría que contar, a no ser la postura original que ese mono adopta en el acto de la reproducción. Todo el mundo sabe que los monos en sus aćtos más íntimos demuestran tener la menor dosis posible de pudor; y debido a esa particularidad todo el mundo ha podido asistir al acto de la generación, coram populo, y en la posición clásica, more canum, en esta familia interesante de animales.

Pues bien, Jimmy constituye una excepción de la regla, pero ¡qué excepción!

Cuando el señor y dueño de la jaula es presa de deseos ardientes de posesión,-y esto llega a ser frecuente-él se sienta en el suelo, las piernas tendidas y unidas, y golpea el piso con la cara dorsal de las manos y los dedos desdoblados. Esta señal debe ser bien conocida de la hembra, pues en cualquier momento que la sorprenda ella vuelve en el acto la cabeza, y sin la menor vacilación, pero pasivamente, se dirige al mono que la espera en la postura ya descrita.

Entonces ella se vuelve de espalda, se sienta sobre los muslos del mono, las piernas separadas al mismo tiempo que ejecuta un movimiento de inclinación hacia los pies de Jimmy,-prosternada por decirlo así-, y en la actitud del musulmán en oraciones.

Durante el acto la hembra queda hasta el final pasiva, asumiendo el macho toda la parte noble y activa de la función...

Vanamente he buscado en los documentos etnográficos refe- 
rentes a este punto especial, algo parecido a lo que acabo de describir... y sin embargo, creo haber encontrado en una relación de viaje reciente por Marruecos, un gesto humano que recuerda el gesto bestial de Jimmy.

“En Marruecos, dice Cristian Houel, en ciertas partes del Mo"ghrob, los hombres tienen que ir a trabajar a largas distancias. "Las mujeres aprovechan su ausencia para escalonarse a lo lar“go de las carreteras, cuidadosamente disimuladas detrás de los "repliegues del terreno, al acecho del viajero.

“Este, al pasar, hace una ligera señal. Ella entonces mira "de cada lado para asegurarse que el transeunte viene solo, y "que nadie pueda sorprenderla.

"Si el examen es favorable y si el hombre le agrada, ella se "desploma de golpe in situ, acurrucada: esto significa: " Ven!"

"'Esos amores salvajes, agrega el corresponsal de guerra ya "citado, este gesto bestial y emocionante, en medio de la inmen"sa e inmóvil soledad, constituye una de las impresiones más "fuertes que pueda llevarse el viajero del país del Moghrb." (Marruecos, por Cristian Houel, Corresponsal de guerra en Marruecos, París.)

En cuanto a Cucusa, los primeros síntomas del embarazo pudieron sospecharse en el mes de agosto de 1914, por el hecho de que en la época catamenial, la turgescencia sexual era moderada al mismo tiempo que había disminuído el flujo sanguíneo;cuando se sabe que en las mismas épocas el desarrollo de las parte genitales externas adquiere un volumen a veces monstruoso.

En ese momento también, y el fenómeno duró 3 o 4 semanas, Cucusa perdió su jovialidad acostumbrada, al mismo tiempo que fué desapareciendo el apetito, demostrando por las comidas una repulsión que se traducía alguna que otra vezz por verdaderos vómitos. Muy pronto, no pudo haber duda ninguna sobre su verdadero estado, pues se hacían más prominentes las mámas, sobre todo el pezón, y el vientre ofrecía, ya un volumen sensible a la vista ; al mismo tiempo que desaparecía toda señal de menstruación en los tres últimos meses del embarazo. (Fig. núm. 2.) De modo que queda demostrado un hecho declarado dudoso en esta frase de la notable Miemoria de Broca sobre el orden de los Primates: en cuanto a los antropoides, la cuestión del flujo cata- 


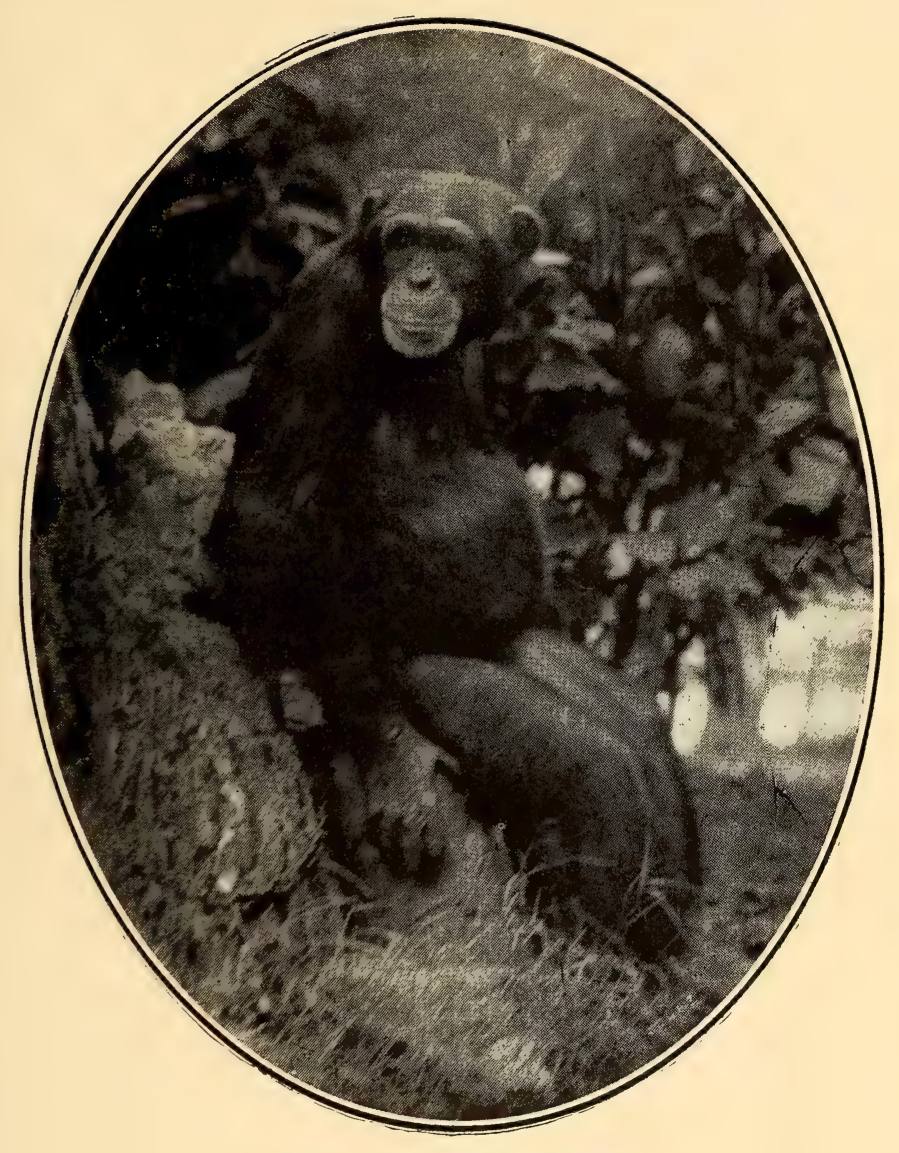

Fig. núm. 2. Cucusa. 



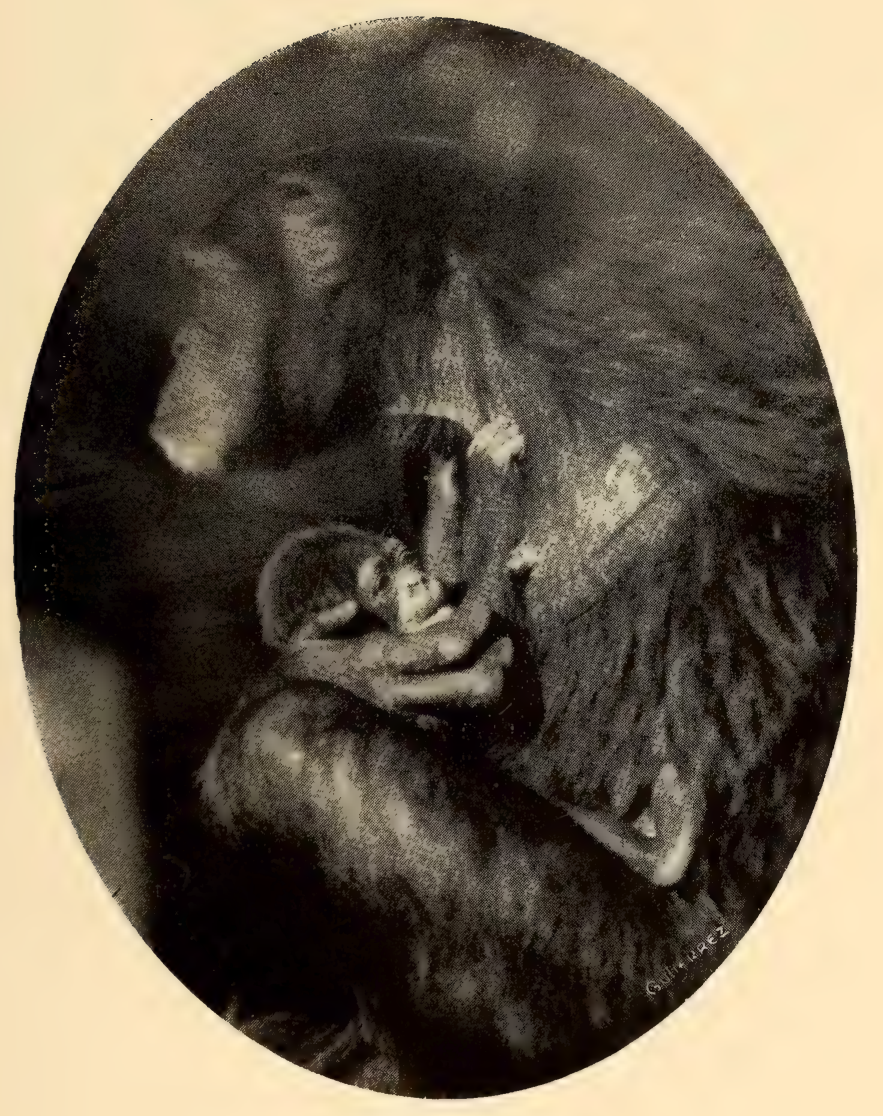

Fig. núm, 3. Anumá. 

menial ha quedado dudosa hasta ahora, puesto que no ha habido ocasión de estudiar en cautiverio, las hembras adultas.

Cucusa, en estado normal, tiene pérdidas sanguíneas a veces abundantes, en la época catamenial.

Otro detalle debe figurar aquí que interesa a los naturalistas. Contra lo que se observa en la mayor parte de los mamíferos, las relaciones sexuales de Jimmy y Cucusa han tenido lugar durante todo el tiempo de la gestación-de día como de noche-desvaneciéndose así la hermosa leyenda, la pretendida característica del hombre sacada de su deplorable aptitud a conducirse..... como Jimmy.

"Se suele repetir, dice a ese respecto Broca, que lo que dis"tingue al hombre del bruto, es el cohabitar en todo tiempo. $\mathrm{He}$ "creído, sin embargo, poder recordar, de paso, que el hombre en"cuentra imitadores entre los brutos."

En fin, después de 9 meses, más o menos, desde los primeros síntomas visibles, Cucusa dió a luz el 27 de abril de 1915, quedando así también demostrada la duración de la gestación de los antropoides, dada hasta ahora como desconocida, por más que se sospechaba que debía durar más o menos el tiempo que acabamos de indicar.

El parto de la mona antropomorfa debió resultar entre 5 y 6 de la mañana. Puesto que a las 6, hora en que el animal pudo ser observado por primera vez, el monito había nacido, descansando ya entre las piernas dobladas de la madre, unido todavía a ella por el cordón umbilical-el cuerpo desprovisto de pelos, excepto en la cabeza, en que se notaban abundantes-, los ojos grandemente abiertos y con mirada azorada. (Fig. núm. 3.)

Algo, pues, escapa a nuestra curiosidad: la actitud de la madre en el acto del parto. Sin embargo, todo nos induce a creer que la postura obstétrica adoptada por Cucusa fué la actitud agachada e inclinada hacia adelante, como pasa en los demás monos. Más aún, parece bien que eso constituya la verdadera postura que adoptaron en tiempos remotos las mujeres de todas las razas humanas.

Pues siempre, y donde dibujos más o menos perfectos nos suministran documentos sobre las costumbres de remota antigüedad, encontramos reproducción de escenas de partos en que se ve 
a la parturiente descansando sobre los dedos de los pies, sobre las rodillas o aun sobre las manos, mientras viene a ayudarla la partera colocada detrás de ella.

Sólo más tarde, es cuando las mujeres se pusieron a dar a luz sentadas sobre las rodillas de una persona, obligando así a la matrona a operar por delante.

A las 7 de la mañana, el cordón apareció separado de la madre, pero adherente al ombligo del joven chimpancé. Nadie ha asistido a la sección del cordón; y sólo se pueden recoger sobre el colchón, en que está tendida la mona, la extremidad placentaria del cordón, con parté de las membranas y dos coágulos, en uno de los cuales el hábil y concienzudo histólogo de la Facultad de Medicina, Dr. Valentín Castanedo, ha podido descubrir un pequeño cotiledon placentario, según consta en la preparación presentada a la "Sociedad Poey".

Es tanto más de sentir que no hayamos podido en este caso obtener la placenta, cuanto que no se sabe nada de las placentas de los antropomorfos. Sólo una vez ha podido estudiarse este órgano en una hembra de chimpancé, por M. Owen,--(R. Owen. The anatomy of vertebrats, 1869) que encontró el órgano simple, discoide, del cual partía una vena umbilical, todo lo cual está comprendido dentro del tipo humano.

Ahora bien, y por más que esto pudiera parecer un hors d'oeuvre, no resisto al deseo de daros a conocer la descripción completa tan sugestiva como instructiva del parto de una mona corriente por madame Louise Toussaint, partera de una cultura excepcional y publicista de talento, hija del naturalista Toussaint.(1)

Durante un viaje en Argelia tuvo ocasión de asistir al parto de una mona perteneciente a la especie conocida bajo el nombre de "Magoto africano". Acostumbrada a verla todos los días, ella notó su ausencia una mañana, y se dirige hacia la arboleda que rodea la casa de vivienda. Aquí dejo hablar a la sagaz observadora :

"Al acercarme, me pareció oir ligeros gemidos; y al levantar "la cabeza pude advertir a la mona sentada sobre la división "que formaban dos gruesas ramas de una soberbia higuera.

(1) Louise Toussaint. Causeries d'une accoucheuse. De este libro he tomado algunos datos, especialmente en lo relativo a la placentofagia. París, 1910. 


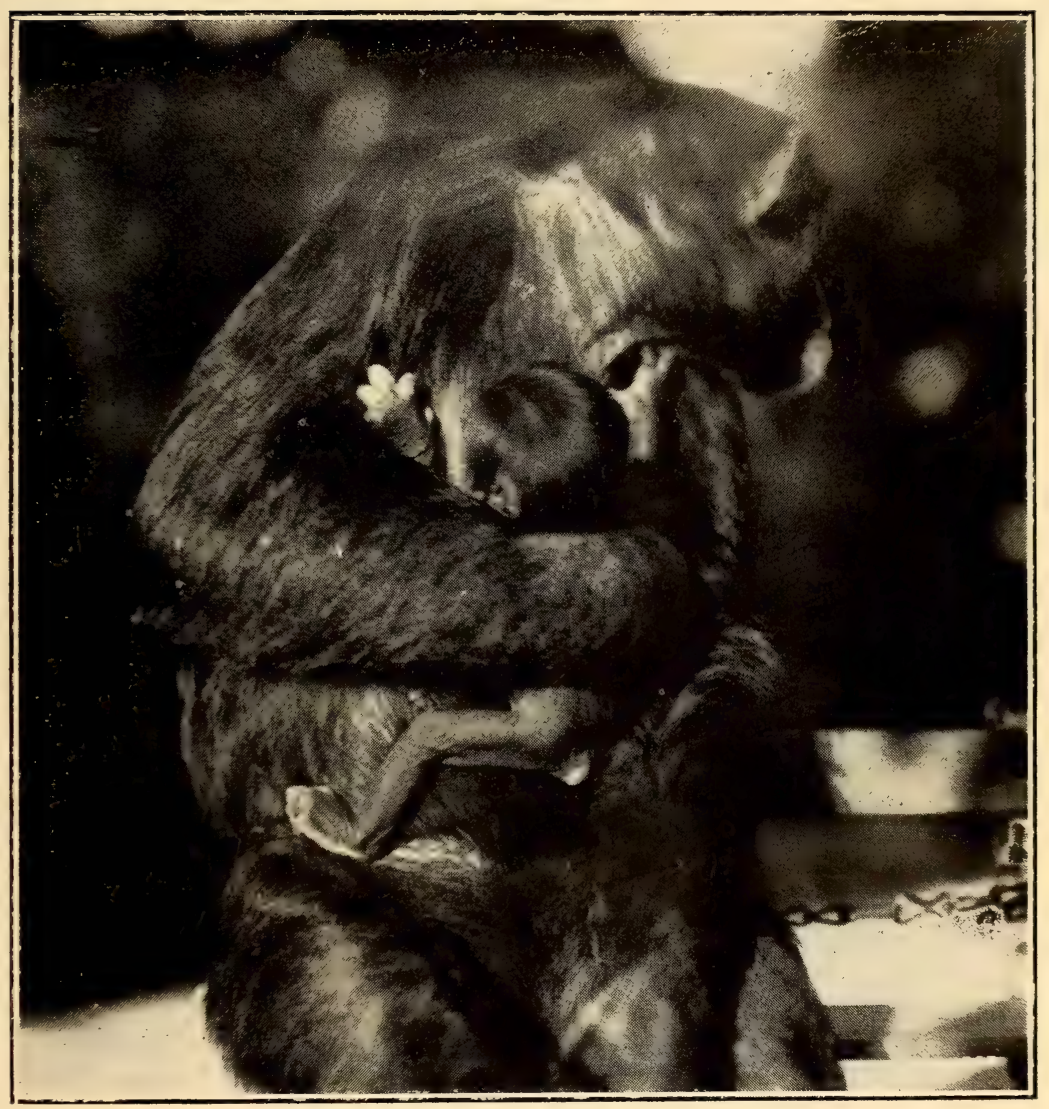

Fig. núm. 4. Cucusa dando de mamar a Anumá. 

"No había duda ninguna para mí, que estaba en los momen"tos del parto.

"Apoyada al tronco del árbol fuertemente asida de las ma"nos y de los pies a la rama sobre la cual se había estableci"do, yo la veía pujar, como una mujer de parto, por esfuerzos "que se traducían por suspiros mal reprimidos. De pronto ví " "aparecer en la vulva, por el occipucio, una cabecita obscura que "no tardó en desprenderse. La mona, en un gesto de prudencia

"maternal, llevó allí la mano, afortunadamente; pues tras de una "contracción, en medio de una onda líquida, los hombros a su "vez se desprendieron bruscamente y el recién nacido hubiera "fatalmente caído al suelo, si la mona, avisada ya, no lo hubiera, "en un movimiento ágil, llevado inmediatamente hacia adelante.

"Siempre agachada, y antes de la expulsión de la placenta, " no seccionado todavía el cordón flotante debajo del vientre, la "mona procedió a una toilette sumaria de su progenitura. De "golpe, la joven madre se detuvo, como inmovilizada por un "nuevo cólico. Tuvo el mismo gesto que en el momento de la "expulsión precedente. Su mano, pasando entre las piernas, se "dirigió rápidamente a la vulva, y allí, en un esfuerzo último, "en medio de un chorro poco abundante de sangre, recibió la pla"centa que se escapaba....

"A la vista de esa masa informe y sanguinolenta, que no da"ba ninguna señal de vida, manifestó una viva sorpresa; y se "puso a darle vuelta en todos sentidos para asegurarse de que. "no era otro pequeño Magoto....

"Al fin y al cabo se atrevió a lamerla. Asistia por vez pri"mera a un parto verdaderamente natural; ¿qué iba a hacer "la mona con el cordón umbilical? Nótese bien, que desde el pri"mer momento ella había seguido una conducta sbsolutamente "conforme a la enseñanza del Dr. Budin. Ella no había seccio"na el cordón, en tanto que la placenta no había sido expulsada.

"Seguramente que no existía ya el menor latido en los vasos "funiculares. Las últimas contracciones uterinas habían expri"mido el disco placentario de la mayor parte de la sangre que "contenía, y la había hecho penetrar en la circulación del recién "nacido que respiraba ampliamente. Las condiciones fisiológicas "eran perfectas.

"No puedo asegurar-es siempre la partera que habla-que "Ia mona se hiciera a sí misma todo este razonamiento obstétri- 
"co ; pero el hecho es, que siguió lamiendo su placenta, con una " "atención sostenida. La había colocado sobre la rama que le ser"vía de asiento, y la mantenía así con la mano derecha, mientras "que con la izquierda ella apretaba el monito contra su vientre, "dándole como punto de apoyo sus dos muslos doblados.

“Más lamía la placenta, y más placer parecía experimentar, a tal punto, que en un momento dado,-no sin alguna vacilación " "-su golosina le impulsó a mordiscar ligeramente la masa. El "ensayo fué favorable, pues ella volvió a hacer 10 mismo, y en "algunos minutos, ella absorbió la parte más carnosa de ese man“jar que probaba por primera vez.

"Sólo en ese momento fué cuando, satisfecho su apetito, ella " pareció darse cuenta de la presencia del cordón que flotaba entre "sus piernas, y se encontraba todavía fijado al ombligo del pe“queñuelo. Ella lo cogió en su mano, lo olfateó, lo mordiscó pri"mero muy suavemente, y poco a poco se puso a roerlo. La sec"ción se hizo rápidamente y de un gesto despreciativo, ella tiró “"al pie del árbol-sobre el cual acababa de cumplir tan rápi"damente esas diversas operaciones-, los restos de su comida "obstétrica."

Todo nos permite, pues, creer que Cucusa devoró su placenta, como la devoran todas las monas que paren en el parque de la "Quinta Palatino".

Pues bien, hay que saber que todas las hembras de mamíferos ingurgitan las envolturas fetales de sus progenituras.

¡Es una necesidad fisiológica para ellas!

Aún más, las mujeres mismas, en ciertas circunstancias no desdeñan seguir su ejemplo. Por lo demás en la especíe humana es una costumbre vieja como el mundo (por más que se encuentre algo abandonada) la que se refiere a comer placenta.

En América, en Asia, en Occeanía, en Africa, en ciertas regiones de Europa existen todavía hoy tribus placentófagas cuyas mujeres han conservado las viejas tradiciones de la especie.

Todo esto suscitaba la risa, o hacía encogerse de hombros, hace apenas algunos años, antes de los trabajos de Brown Sequard y la reconstitúción de los métodos opoterápicos. Pero hoy, nadie puede ignorar la extraordinaria acción que poseen, sobre nuestros tejidos, los jugos de ciertos órganos.

Pues bien, los jugos placentarios pertenecen precisamente a esta clase: ellos levantan con una singular actividad las fuerzas 
de las recien paridas; restablecen la salud de los órganos genitales y provocan la secreción láctea.

Bouchacourt (1) insiste mucho sobre el hecho que todos los animales, después de la parturición, comen su placenta, lo mismo que los pájaros comen los restos de su cascarón después del nacimiento de los polluelos.

A veces parece ser que ciertas mujeres tienen después del alumbramiento vivos deseos de absorber la placenta. Quizás tenga esa costumbre una significación alimenticia, ya que la placenta, lo sabemos, es rica en sustancias de ahorro. De modo que la placentofagia se explicaría por la influencia que los extractos placentarios ejercen sobre el organismo, en particular sobre las glándulas mamarias.

Hoy la ciencia explica bien todos estos fenómenos.

La glándula tiroidea fabrica efectivamente sustancias orgánicas especiales a base de arsénico, iodo, fósforo,-las que vertidas en la circulación presentan acciones muy complejas-; pero presiden sobre todo a la formación y al funcionamiento de los productos epidérmicos-del cerebro, de los órganos genitales-y del embrión. (Carnot.)

Pues bien, es en el disco placentario donde, durante el desarrollo embrionario de los mamíferos, vienen a acumularse todos los jugos orgánicos indispensables para el desarrollo del nuevo ser. Todo lo que puede producir de esos jugos el organismo femenino, aun a riesgo de comprometer la integridad àe sus propios tejidos, se almacena eṇ ese punto.

En el momento del alumbramiento, las contracciones expulsivas de la matriz, al comprimir largo tiempo la placenta, contribuyen felizmente-en cierta medida-a facilitar la reabsorción por la madre, de una parte de esas reservas que serán pronto utilizadas. Pero con todo, una gran parte es arrastrada al exterior con el alumbramiento. Esto constituye una pérdida sensible para el organismo.

Pues bien, he ahí cómo el instinto natural interviene con utilidad. Excita a la madre, aun cuando pertenezea a una especie para la cual toda alimentación cárnea es habitualmente un objeto de repulsión, a no dejar desaparecer así las preciosas reservas alimenticias sacadas de su propia sustancia, y que tienen para

(1) Opoterapia, por el Dr. Paul Carnot. París, 1911. 
ella, en este momento preciso, un valor especial. El mismo instinto provoca un extraño apetito funcional, que le va a hacer ingurgitar e ingerir sus secundinas.

Toda hembra que pueda absorber todo o parte de su placenta se repone de su parto, y la lactación se establece en ella más rápida, más abundante. He ahí un fenómeno que nadie puede negar hoy por hoy.

Hemos aludido, durante la narración del parto de la mona "Magoto", al Dr. Budin.

Todos sabemos que el Dr. Budin, ha demostrado qué importancia tenía, en el momento del alumbramiento, el hecho de no ligar el cordón sino cuando los vasos de éste han cesado de latir. El niño gana así unos cien gramos de sangre suplementaria que le proviene de la placenta.

De modo,-dice Madame Toussaint-si la mujer diera a luz en condiciones conformes con las leyes naturales, no ligaría nunca su cordón. Después de la expulsión del feto, esperaría tranquilamente la expulsión de la placenta. Sólo en ese momento-cuando ya los vasos funiculares hubieran cesado de latir-separaría la placenta y comería de ella, probablemente con tanto gusto como provecho, una buena tajada.

Después de esta digresión que he creído interesante, sobre la placentofagia, volvamos a la madre y al joven antropomorfo.

Los dos primeros días Cucusa, algo fatigała, se acuesta a cada rato boca arriba; pierde poca, muy poca sangre; y desde el tercer día puede fácilmente trepar a la tabla horizontal, algo elevada, que se encuentra por encima de su cama y le sirve de lugar de descanso.

Desde el segundo día sê nota la aparición de la leche, que se ha conservado abundante hasta hoy. (Fig. núm. 4.)

El 13 de Mayo, es decir, 16 días después del parto, vuelta aparente de las reglas,--abundantes durante 24 horas-pero sin turgescencia genital externa. Desde entonces no se ha presentado nada hasta hoy, ya en el sexto mes.

En cuanto a Anumá, el cordón umbilical, seco y aplastado, ha seguido adherido durante unas 36 horas después del nacimiento: hemos tenido cuidado de recogerlo y mide 70 centímetros.

Sabemos, por el examen del Dr. V. Castanedo, que ofrece la constitución normal, humana. 
A los dos meses le han salido 4 incisivos: 2 arriba, 2 abajo. Durante el tercer mes los incisivos restantes han hecho su aparición.

A los 4 meses han brotado 4 molares; actualmente tiene 6 meses.

Anumá presenta una talla de 53 cent.; la circunferencia de la cabeza es de 33 cent.; su perímetro torácico mide 37 cent.

$\mathrm{Y}$ aquí terminamos las notas anatómicas o fisiológicas del caso. En cuanto a las relaciones familiares entre madre, hijo y padre, se podría hacer un estudio de los más originales, digno ciertamente de ocupar la atención del más sutil psicólogo.

Desde el día del alumbramiento han quedado separados los dos cónyuges. Pero la hembra sigue mostrándose sensible al gesto del mono, y como siempre ella viene a tomar la posición original conocida, contra la reja.... que se opone a la unión deseada.

"El gallo, dice una notable pensadora, canta siempre la misma canción, y esa canción la gallina la encuentra siempre divina." 





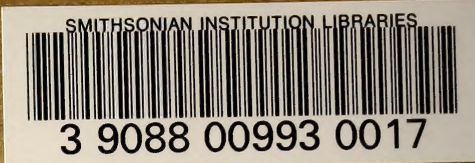

